\title{
UV-nanoimprint lithography and large area roll-to-roll texturization with hyperbranched polymer nanocomposites for light-trapping applications ${ }^{\text {th }}$
}

\author{
Marina A. González Lazo ${ }^{a}$, Rémy Teuscher ${ }^{a}$, Yves Leterrier ${ }^{a}$,*, Jan-Anders E. Månson ${ }^{a}$, \\ Caroline Calderone $^{\mathrm{b}}$, Aïcha Hessler-Wyser ${ }^{\mathrm{b}}$, Philippe Couty ${ }^{\mathrm{c}}$, Yvan Ziegler ${ }^{\mathrm{c}}$, Diego Fischer ${ }^{\mathrm{c}}$ \\ a Laboratoire de Technologie des Composites et Polymères (LTC), Ecole Polytechnique Fédérale de Lausanne (EPFL), CH-1015 Lausanne, Switzerland \\ ${ }^{\mathrm{b}}$ Centre Interdisciplinaire de Microscopie Electronique (CIME), Ecole Polytechnique Fédérale de Lausanne (EPFL), CH-1015 Lausanne, Switzerland \\ ${ }^{\mathrm{c}}$ Flexcell (VHF-Technologies SA), Rue Edouard-Verdan 2, CH-1400 Yverdon-les-Bains, Switzerland
}

\section{A R T I C L E I N F O}

\section{Article history:}

Received 8 December 2011

Received in revised form

21 March 2012

Accepted 23 April 2012

Available online 16 May 2012

Keywords:

Hyperbranched polymer

Nanocomposite

UV nanoimprint lithography

Light-trapping

Roll-to-roll

Amorphous silicon

\begin{abstract}
A B S T R A C T
Light-trapping textures were produced in hyperbranched polymer (HBP) silica nanocomposites using a UV-nanoimprint lithography (UVNIL) replication method, either in batch or roll-to-roll processes. The hardness of the HBP was found to increase by a factor of 2.5 with the addition of $50 \mathrm{vol} \%$ of nanoparticles. A nickel master with random sub-micron pyramidal structures was used to imprint nanocomposites containing up to $20 \mathrm{vol} \%$ of silica on a polyethylene naphthalate (PEN) substrate. The influence of nanoparticle fraction and pressure on the texture morphology and light scattering properties of the replicas was studied using scanning electron microscopy and optical analysis. The roughness and coherence length of the textures were similar to those of the master for all investigated compositions and process pressures. Likewise, the light scattering performance of aluminum-coated texturized nanocomposites was identical to that of the metal template, with a haze of $90 \%$ over the 400-800 nm spectral range. Thin film amorphous silicon solar cells were deposited on the texturized substrates using a large-area roll-to-roll process. The photocurrent of these devices was found to be $23 \%$ higher than the reference value of a flat cell.
\end{abstract}

(c) 2012 Elsevier B.V. All rights reserved.

\section{Introduction}

The addition of nanoscale textures to the back reflector of a photovoltaic (PV) device is a way to enhance light absorption while keeping the active material thickness to its minimum [1,2]. The principle is to manipulate the direction of the light reflected from the back surface to increase its path length inside the device. For an optimum light confinement, the surface feature dimensions should have sizes close to the wavelengths of light that have to be scattered [3]. A lot of work has been done in the past two decades to understand the interaction between light and rough surfaces, with focus on the influence of texture geometrical features on the light scattering process [4-6]. Regular pyramidal patterns showed better light trapping properties than random ones, but with a higher geometrical sensitivity [7]. Nevertheless, thin film silicon cells deposited on a random pyramidal relief showed an improved efficiency compared with cells deposited on a flat substrate $[8,9]$. Several methods for creating rough surfaces

\footnotetext{
Parts of this work were presented at the 21st International Photovoltaic Science and Engineering Conference, PVSEC21, Nov. 28 Dec. 2, 2011, Fukuoka, Japan.

* Corresponding author. Tel.: +41216934848.

E-mail address: yves.leterrier@epfl.ch (Y. Leterrier).
}

on back reflectors were reported. In the case of hard glass or metal substrates, low-pressure chemical vapor deposition (LP-CVD) of $\mathrm{ZnO}$-based transparent conductive oxides (TCOs) led to pyramidal crystal structures with efficient light scattering properties [10]. In the case of soft thermoplastic substrates, thermal nanoimprint lithography enabled replication of the mold patterns, however with a limited shape fidelity. In addition, the high pressure ( $\sim 200$ bar) and high temperature $\left(\sim 200{ }^{\circ} \mathrm{C}\right)$ [11] required to imprint the polymer surface could make it not cost effective [11-13]. Ultraviolet nanoimprint lithography (UVNIL) is a wellestablished process for the replication of sub-micron scale features into photopolymerizable resins. Different shapes as gratings or stellar like structures with dimensions between $30 \mathrm{~nm}$ and $100 \mu \mathrm{m}$ have been successfully transferred into silicon wafers with good dimensional stability [14]. The low pressure ( $\sim 6$ bar) and room temperature imprinting conditions were favorable for roll-to-roll fabrication of high quality patterns on polymer substrates [15].

Among the UV-curable resins, hyperbranched polymers (HBP) were found to be well suited for nano-replication due to their low polymerization shrinkage and internal stress [16]. Acrylated HBPs and nanocomposites were used to fabricate polymer micro- and nano-structures with high accuracy [17]. The addition of nanoparticles to polymer materials led to significant improvement in 
mechanical properties [18]. Polyether ether ketone composites reinforced by nano-sized $\mathrm{SiO}_{2}$ particles exhibit improved Young's modulus, ultimate tensile strength and thermal stability [19]. Sugimoto et al. [20] also demonstrated increasing microhardness values with the introduction of reactive silica nanoparticles in poly(methyl methacrylate). Moreover, the addition of $20 \mathrm{vol} \%$ silica particles into an acrylated HBP reduced polymerization shrinkage of the HBP up to $26 \%$ [21]. The combination of low shrinkage and improved hardness of HBP nanocomposites should be useful to replicate high fidelity light trapping nanotextures with a high thermo-mechanical stability, suited for PV device applications. It was in fact shown that so-called 'hard-coat' nanocomposite layers improve the mechanical integrity of brittle inorganic films on polymer substrates. These nanocomposite layers buffer the negative influence of the soft and rough surface of the polymer, thus reducing the number of defects in the films [22]. They also reduce the elastic contrast between the inorganic films and the substrate, hence increase the critical failure strain of the films [23]. However, the considerable increase of viscosity of the HBP precursor monomer upon addition of nanoparticles may compromise the low-pressure replication process. For instance, the viscosity of HBP increased by 5 orders of magnitude upon addition of $10 \mathrm{vol} \%$ of $13 \mathrm{~nm}$ silica particles due to $\mathrm{H}$-bond interactions [24]. The replication fidelity could also be compromised because the internal stress increases with nanoparticle fraction $[25,26]$

The objective of this work was threefold. The first was to study the influence of nanosized silica fillers and process pressure on (i) the hardness of the composites and (ii) the shape fidelity of submicron random pyramidal textures replicated from a metallic master. The second objective was to scale-up the texturization of the polymer-based materials from a small area batch process to a large area roll-to-roll process. The third objective was to evaluate the photovoltaic performance of thin film amorphous silicon devices deposited on the roll-to-roll texturized substrates.

\section{Experimental section}

\subsection{Materials and processing}

The hyperbranched polymer was a polyester acrylate oligomer with functionality of 16 and a glass transition temperature in cured state equal to $165{ }^{\circ} \mathrm{C}$. The photo-initiator was in a concentration equal to $6 \mathrm{wt} \%$. The particles were in the form of a suspension of $30 \mathrm{wt} \%$ monodispersed $\mathrm{SiO}_{2}$ in isopropanol. The average particle size was $13 \mathrm{~nm}$, which corresponds to a specific surface area of about $230 \mathrm{~m}^{2} / \mathrm{g}$. Composites with up to $50 \mathrm{vol} \%$ (65 wt\%) of $\mathrm{SiO}_{2}$ particles were prepared as follows. First, the photo-initiator was dissolved in the HBP at $75{ }^{\circ} \mathrm{C}$ and stirred for $15 \mathrm{~min}$. The selected amount of $\mathrm{SiO}_{2}$ suspension was then added to the HBP and the mixture was stirred for one hour. The solvent was evaporated at $60{ }^{\circ} \mathrm{C}$ under vacuum until no more weight variation of the suspension was detected. A $200 \mathrm{~W}$ mercury bulb UV lamp (OmniCure 2000, Exfo, Canada) was used for all experiments. The light intensity was measured using a calibrated radiometer (Silver Line, CON-TROL-CURE, Germany), between 230 and $410 \mathrm{~nm}$.

The thermomechanical properties (glass transition temperature, Young's modulus, viscoelastic properties, coefficient of thermal expansion and thermal stability) of the HBP and HBP nanocomposites were investigated in a previous study [27]. For all investigated silica fractions in the range of $0-20 \mathrm{vol} \%$, these materials were found to be stable up to approximately $400{ }^{\circ} \mathrm{C}$. The addition of silica to the HBP did not significantly improve the thermal stability of the polymer. This temperature is

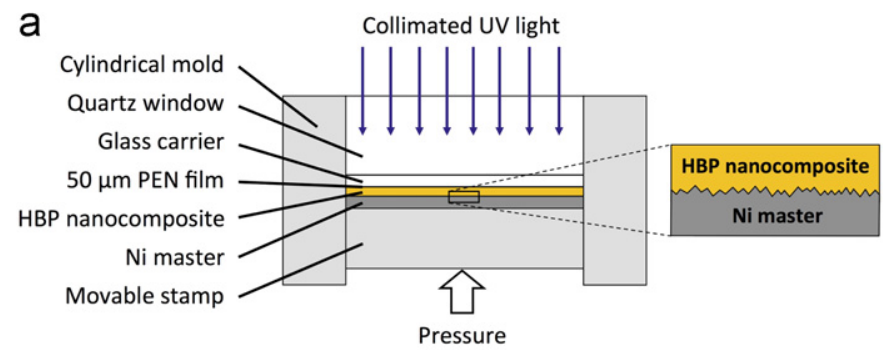

b

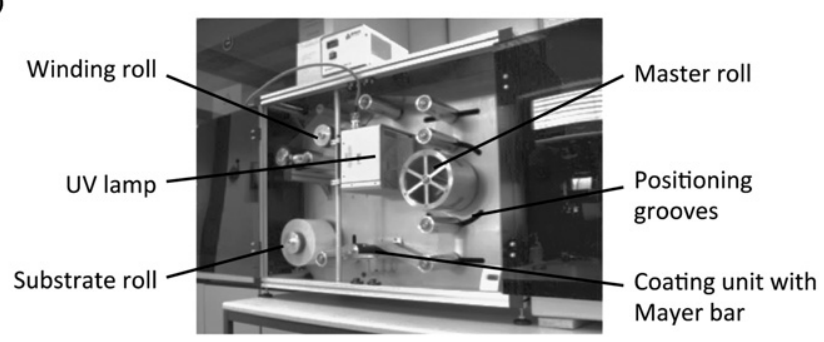

Fig. 1. Sketch of the UVNIL tool (a) and photograph of the roll-to-roll pilot process $(18 \mathrm{~cm}$ wide web, b)

far above the deposition temperature of the active PV layers $\left(150-180^{\circ} \mathrm{C}\right)$ and the melting point of the PEN substrate $\left(270{ }^{\circ} \mathrm{C}\right)$, i.e., there was no risk of degradation of the HBP-based coatings during further process operations.

A UVNIL tool designed and built in-house was used, as detailed in Ref. [25]. The tool sketched in Fig. 1 consists of a cylindrical steel mold equipped with a UV-transparent quartz window. Pressure was applied using a pressure-controlled pneumatic movable stamp to which was attached the master. The master was a nickel random pyramidal structure electrochemically replicated from a $\mathrm{ZnO}$ texture grown by CVD [28], and produced in the form of a $40 \mathrm{~cm} \times 60 \mathrm{~cm}, 50 \mu \mathrm{m}$ thick foil. A $2 \mathrm{~cm} \times 2 \mathrm{~cm}$ square was cut from the foil to fit into the UVNIL tool. Geometrical features of the nickel master are provided in Section 3. Approximately $100 \mathrm{mg}$ of nanocomposite was dispersed on the master and covered with a $50 \mu \mathrm{m}$ thick PEN film and a glass slide to ensure a homogeneous pressure across the sample surface. Pressures of 1, 3 and 6 bar were tested with $\mathrm{SiO}_{2}$ fractions up to $20 \mathrm{vol} \%$. All samples were irradiated during $3 \mathrm{~min}$ at the maximum lamp intensity. To ensure the same irradiation conditions for all samples, the light intensity was measured under the glass slide, at the sample surface.

\subsection{Roll-to-roll manufacture of texturized coatings and photovoltaic} cells

Roll-to-roll processing enables cost-effective manufacture of flexible solar cell devices, which is required to meet the price target of applications [29]. An $18 \mathrm{~cm}$ wide web roll-to-roll line equipped with a coating unit, a roll coated with a Ni foil with the same texture as used for the batch tests, and a UV lamp was developed and is shown in Fig. 1. A Mayer bar with $50 \mu \mathrm{m}$ diameter wire was used to meter the formulation coating on the PEN substrate, leading to a final thickness of $3 \mu \mathrm{m}$. The layer thickness was measured from micrographs taken in reflection mode of the cross-section of cured coatings on PEN samples, embedded in an epoxy resin and carefully polished. A light shield was placed between the coating unit and the roll. The position of the shield, UV lamp and imprinting roll could be adjusted depending on the kinetics of the photopolymerization reaction. This was key to ensure appropriate timing of the imprinting process with respect to the gelation of the resin. Curing was achieved with a Dymax $400 \mathrm{~W}$ metal-halide UV source with an 
intensity of $60 \mathrm{~mW} / \mathrm{cm}^{2}$ and a temperature close to $60{ }^{\circ} \mathrm{C}$. Several 20-100 m long rolls were produced with the unfilled HBP and a 5 vol\% silica nanocomposite at a line speed of $7 \mathrm{~cm} / \mathrm{min}$.

Thin film amorphous silicon solar cells were deposited on the roll-to-roll texturized HBP coated substrates. Single a-Si junction cells were grown using standard PECVD reactors. The back reflector was made of sputtered $\mathrm{Ag}-\mathrm{ZnO}$ and ITO was used as surface TCO. The deposition temperature of the active layers was in the range of $150-180^{\circ} \mathrm{C}$.

\subsection{Characterization techniques}

The microhardness of the UV-cured materials was measured using a Vickers indenter (Miniload microhardness tester, Leitz, Germany). Approximately $300 \mu \mathrm{m}$ thick coatings were prepared on glass slides. The coating thickness was more than ten times the indentation depth (approximately $20 \mu \mathrm{m}$ ) to avoid substrate artifacts [30]. All samples were irradiated during $3 \mathrm{~min}$ at the maximum lamp intensity. The hardness $H$ (in $\mathrm{MPa}$ ) was calculated as

$H=1.854 P / d^{2}$

where $P$ is the force (in N) and $d$ is the mean diagonal length of the indentation (in $\mathrm{mm}$ ). The factor 1.854 comes from the geometry of the pyramidal indenter with face angle equal to $136^{\circ}$. A force of $0.49 \mathrm{~N}$ and an indentation time of $15 \mathrm{~s}$ were fixed for all samples. The hardness values were measured immediately after indentation and at least five measurements were taken for each $\mathrm{SiO}_{2}$ concentration. Optical micrographs of the samples were taken using an Olympus BX60 optical microscope and the two diagonals (typically $100 \mu \mathrm{m}$ ) of the pyramidal indentation were measured with $\sim 1 \mu \mathrm{m}$ accuracy.

For optical characterization, all samples were coated with a $100 \mathrm{~nm}$ thick sputtered aluminum film (nickel template and batch replicas) and evaporated aluminum film (PEN substrate and roll-to-roll replicas). Angle resolved scattering (ARS) measurements were carried out in reflection mode using an in-house set-up equipped with a red light laser source $(637 \mathrm{~nm})$. The haze of the texturized surfaces (ratio of scattered light to total reflected light) was measured in the $400-800 \mathrm{~nm}$ range using a $10 \mathrm{~W}$ halogen lamp, an integrating sphere and a spectrometer (AvaSpec-2048).

A direct relation exists between the microscopic features of a texture such as roughness and its light scattering performance and resulting increase in photocurrent of a deposited PV cell [31]. The topography of the texturized samples was examined by scanning electron microscopy (SEM). This technique was preferred to atomic force microscopy (AFM) since it provides accurate morphological data over a vast length scale, which is particularly well suited to characterize random structures with $\mathrm{nm}$ to $\mu \mathrm{m}$ features. In contrast to AFM, SEM is a noncontact method, free of probe-surface contact problems such as tip convolution effect, tip wear, and risk of surface deformation and damage in the case of soft polymer surfaces. Three-dimensional reconstructions of SEM images are moreover highly reliable and correlate with AFM data (see e.g. Refs. [32,33]). The SEM (FEI XL30-SFEG) was operated in ultra-high resolution mode (UHR), using an acceleration voltage of $5 \mathrm{kV}$. The working distance was usually $5 \mathrm{~mm}$. The samples were coated with a $\sim 10 \mathrm{~nm}$ thick film of carbon to avoid charging effects. The root mean square (RMS) roughness and the coherence length $(L)$ of the textures were computed using three-dimensional (3D) reconstructions of the micrographs. For each sample, three images were taken at different tilt angles ( $-10,0$ and 10 degrees) and 3D reconstructions were done using the software MeX (Alicona). This software generates a stereoscopic image combining the images of the tilted top-views and directly calculates the RMS roughness. The RMS roughness and $L$ give information about the vertical and lateral sizes of the pyramids, respectively and these parameters control the light-trapping performance of the texture as detailed in Ref. [34]. The $L$ value was determined by the diameter of the disk obtained by cutting the autocorrelation peak at a distance of $1 / \mathrm{e}$ of its maximum, using the software WSxM [35] with a homemade program for data treatment. The uncertainty on the RMS roughness and $\mathrm{L}$ values was determined using five reconstructions made from five different locations on the sample, and was found to be equal to $8 \%$ and $18 \%$, respectively.

Cross-section images of the texturized nanocomposite coating were produced using a focused ion beam (FIB FEI Nova 600 NanoLab) coupled with a SEM. First, a thin film of platinum was deposited on top of the sample to protect the surface from possible ionic damages and to keep the surface profile intact. Then, the sample was tilted at an angle of 52 degrees and etched using a focused $\mathrm{Ga}$ ion beam. The images were taken with the electron beam using the same conditions as for the surface topography detailed in the previous paragraph.

The current-voltage (IV) response of roll-to-roll deposited PV devices was measured using an AM1.5 PASAN flash simulator. The external quantum efficiency (EQE) was also measured and the short-circuit current density $J_{\mathrm{sc}}$ was calculated by integrating the EQE vs. spectral density of the photon flux of AM1.5 solar spectrum data over the wavelength range. Cell degradation was performed according to the procedure 10.19 .3 of IEC 61646 , using an illumination of $640 \mathrm{~W} / \mathrm{m}^{2}$ and a temperature of $46{ }^{\circ} \mathrm{C}$ until saturation, i.e. when the power fluctuation was below $2 \%$ for two consecutive measurements. To reduce the heating effect of the cell by infrared radiation, a $6000 \mathrm{~K}$ light emitting diode was used. The PV devices were tested under open circuit conditions, and typical test duration was $1000 \mathrm{~h}$.

\section{Results and discussion}

\subsection{Microhardness of nanocomposites}

The Vickers microhardness of the HBP and nanocomposites is depicted in Fig. 2. The hardness of the HBP was found to be equal to $112 \mathrm{MPa}$. It increased roughly linearly with silica loading, to approximately $200 \mathrm{MPa}$ for $20 \mathrm{vol} \%$ of particles, and to $283 \mathrm{MPa}$ for $50 \mathrm{vol} \%$ of particles. Such an increase is comparable to that observed in other nanocomposite materials [19,36]. The moderate increase at the highest investigated particle concentration of $50 \mathrm{vol} \%$ was attributed to the presence of porosity resulting from the entrapment of air during the mixing process. The hardness of the composite with 50 vol\% of silica was thus not considered in the following analysis. Moreover, it was assumed that the chemical conversion and resulting properties of the HBP matrix were not influenced by the presence of the silica particles (contrary to the results reported in e.g. Ref. [37]). In the present case, the high concentration of photoinitiator and long curing time were expected to limit such influence.

A limited number of models are available to describe the hardness of composite materials. The classic rule-of-mixtures (RoM) was initially proposed by Rice to describe the hardness of crystallized glasses [38]:

$H=\phi H_{\mathrm{SiO}_{2}}+(1-\phi) H_{\mathrm{HBP}}$

where $\mathrm{H}, \mathrm{H}_{\mathrm{SiO}_{2}}$ and $H_{\mathrm{HBP}}$ represent the hardness values of the composite, of silica particles (taken equal to $8.8 \mathrm{GPa}$ [39]) and of $\mathrm{HBP}$, respectively, and $\phi$ is the volume fraction of silica. The rule of mixtures does not take into account the discontinuous nature of the particle assembly and the particle-matrix interactions, and 
thus provides an upper bound. The corresponding lower bound is given by the inverse rule-of-mixtures:

$H=\left[\phi / H_{\mathrm{SiO}_{2}}+(1-\phi) / H_{\mathrm{HBP}}\right]^{-1}$

The upper and lower bounds are shown in Fig. 2. The former bound largely overestimates the data, whereas the latter provides a good estimate at a silica fraction of $5 \mathrm{vol} \%$, and underestimates the data at higher silica fractions. In order to account for the discontinuous nature of the reinforcing phase, a 'strengthening efficiency coefficient' $\eta$ was introduced in the form of a modified RoM [40]:

$H=\eta \phi H_{\mathrm{SiO}_{2}}+(1-\phi) H_{\mathrm{HBP}}$

The coefficient $\eta$ is assumed to be of the order of 0.1 for particles of aspect ratio equal to 1 . In the present case, Eq. 4 was fitted to the experimental data, giving a coefficient $\eta$ equal to 0.055 . Comparable values were reported for other polymer nanocomposites [36]. A further approach was proposed by Goyal et al. [36] using the Halpin-Tsai equation. However, this equation was developed to model the elastic modulus of composites, and may not be relevant for properties such as hardness involving plastic deformations.

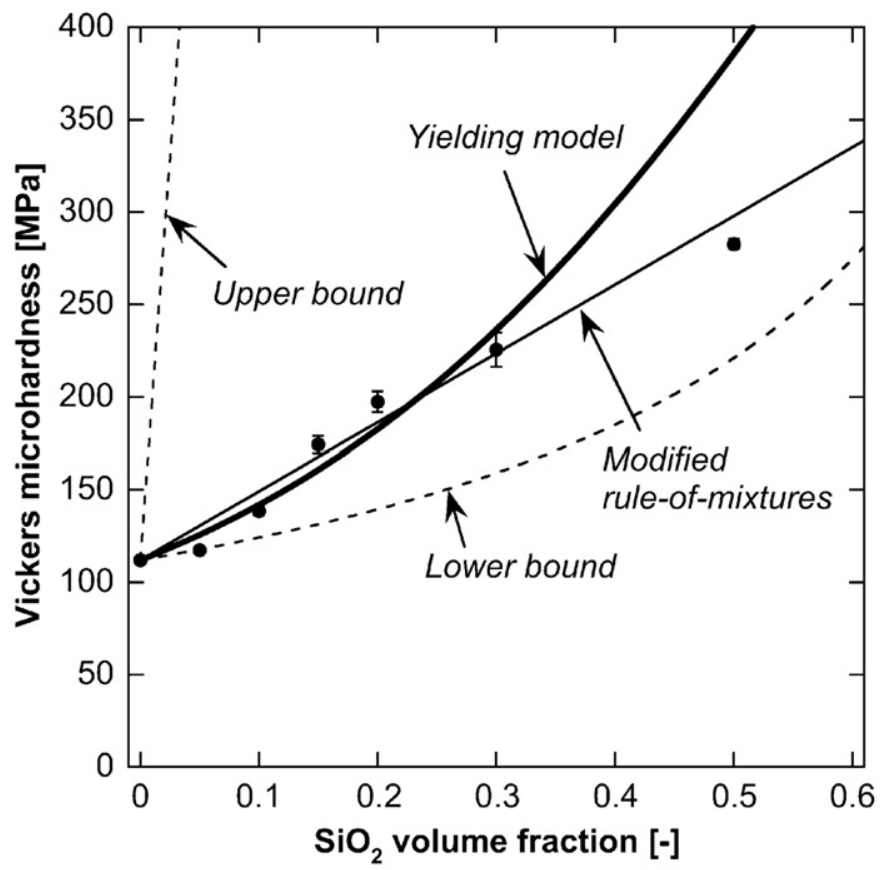

Fig. 2. Vickers microhardness of $\mathrm{HBP}-\mathrm{SiO}_{2}$ nanocomposites vs. $\mathrm{SiO}_{2}$ volume fraction. The dots are experimental data and the lines represent different models as indicated.
We propose an alternative semi-empirical approach based on yield stress arguments, since the indentation experiment involves large plastic deformations. The yield stress of composite materials has been associated with Hashin-Shtrikman elastic bounds [41,42]. Under compressive loading, stress localization around particles and between adjacent particles occurs, thus exacerbating shear yielding processes as investigated in Ref. [43]. In the present work, the yielding model of Pukansky [44] was used, in which the yield stress terms were replaced by hardness:

$H=H_{\mathrm{HBP}} \frac{1-\phi}{1+A \phi} \exp \{B \phi\}$

where the fraction term in the right-hand-side describes the change of effective particle cross-section as a function of particle fraction $\phi$, and $A$ is a shape parameter associated with packing features of reinforcing particles:

$A=\frac{\psi^{*}-\phi^{*}}{\left(1-\psi^{*}\right) \phi^{*}}$

where $\phi^{*} \sim 0.64$ and $\psi^{*}=0.842$ are the random packing volume fraction for spheres, and random packing area fraction for disks, respectively [45], giving $A=1.9976 \sim 2$. $B$ is an interface interaction parameter. The exponential function in Eq. 5 derives from the assumption that the change of property (hardness) with particle fraction is proportional to the property itself. Eq. 5 was fitted to the experimental data (up to $\phi=0.3$ ) with adjustable parameter $B$. The result shown in Fig. 2 was obtained with $B=5.25$, which is among the highest values for $B$ reported in former studies of particulate composites, including values close to 6 for polypropylenesilica nanocomposites [44]. Such a high value reflects the presence of strong interactions at the particle-polymer interface [24], exacerbated by the very high specific interface area (proportional to the particle volume fraction $\phi$ and close to $40 \mathrm{~m}^{2} / \mathrm{g}$ for $\phi=0.1$ ).

\subsection{Nanocomposite textures}

Fig. 3 shows the cross-section of a texturized nanocomposite with $10 \mathrm{vol} \%$ of silica nanoparticles produced using a pressure of 6 bar. The light-gray layer on the top corresponds to the platinum protective layer and the dark layer on the bottom corresponds to the PEN substrate. The nanoparticles are well dispersed in the HBP across the whole coating thickness, with some degree of heterogeneity at the micron level. The resin exudation effect at the surface observed in a previous study of nanocomposite textures [25] was not found in the present case as nanoparticles are also present close to the top surface of the coating. The uppermost bright coating layer is an artifact resulting from charging effects at the platinum interface.

Electron micrographs of texturized HBP and composites are shown in Fig. 4 and their salient features are reported in Table 1.
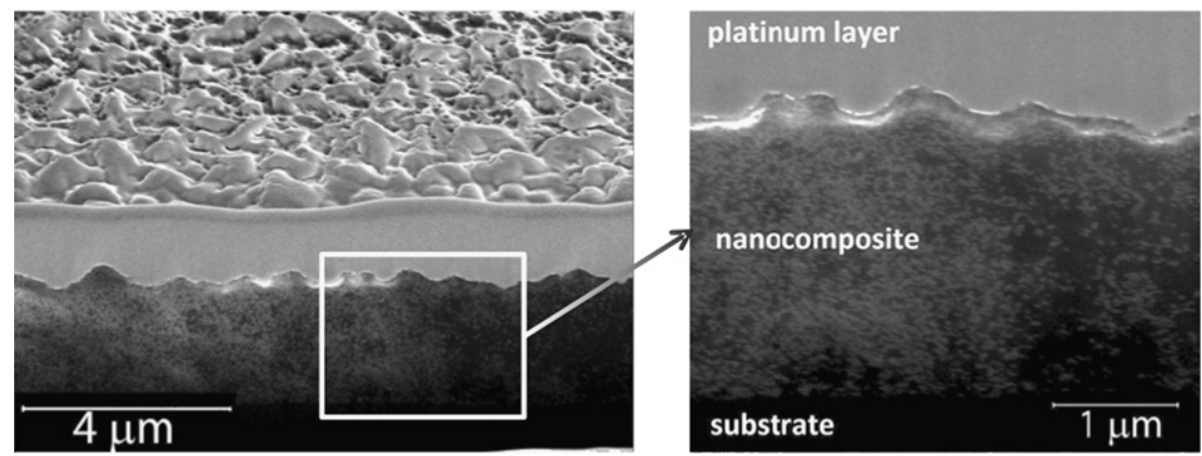

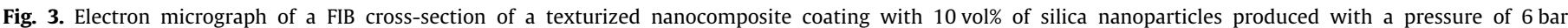
during UVNIL. 

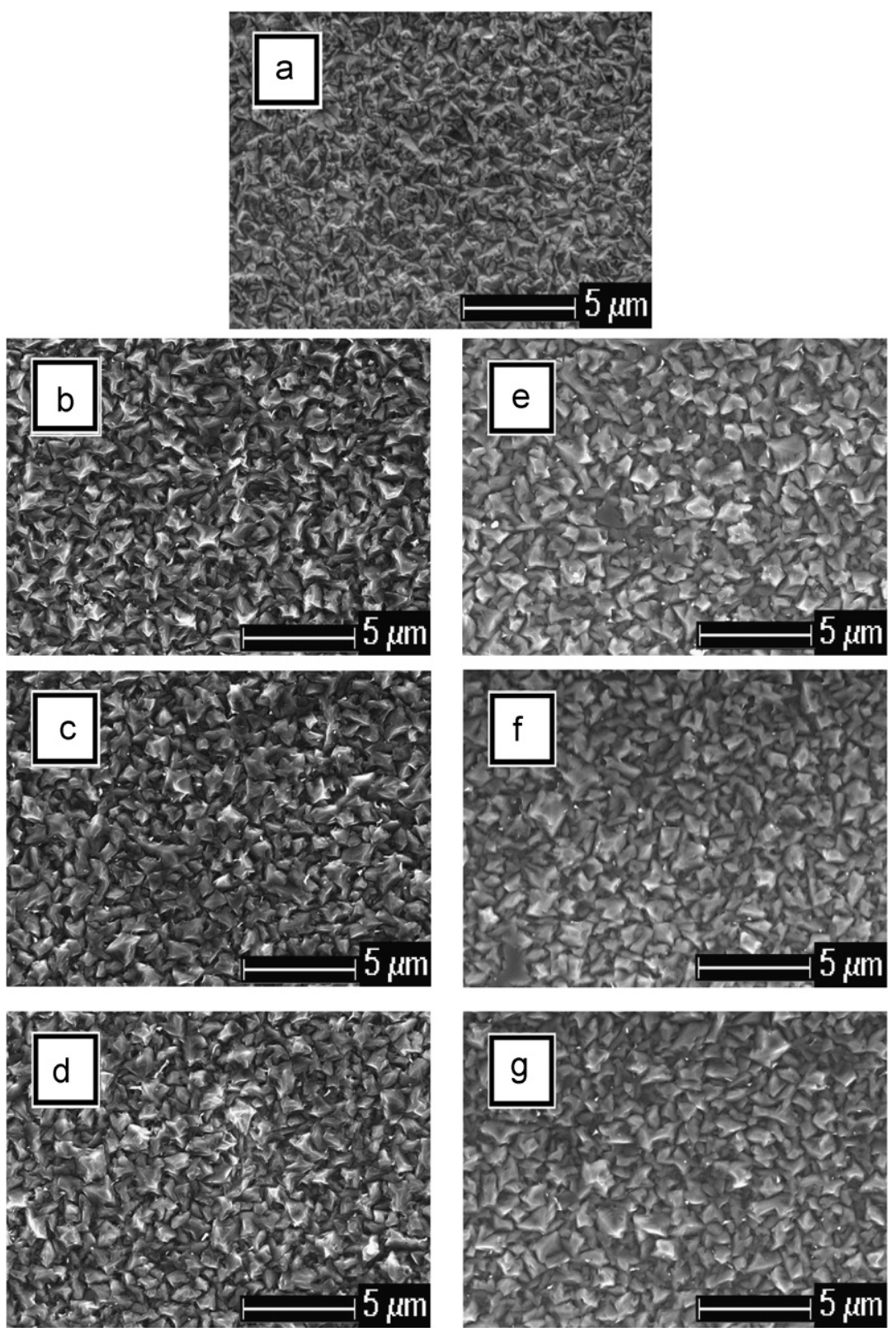

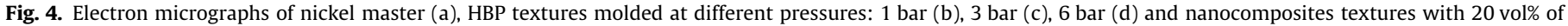
silica molded at different pressures: 1 bar (e), 3 bar (f), 6 bar ( $g$ ).

Fig. 4a represents the surface of the Nickel master, as the inverted pyramidal texture of the original ZnO grown by CVD. The RMS roughness and $L$ value of this texture were equal to $101 \mathrm{~nm}$ and $301 \mathrm{~nm}$, respectively. Fig. 4b-g show the textures produced with the master for different compositions and process pressures. It should be pointed out that the polymer-based replicates are the negative images of the nickel master. In fact the RMS roughness values of negative and positive surfaces are identical, so any significant difference of RMS roughness between replicate and master is due to replication fidelity. The question of light scattering is less obvious, since positive and negative textures with peculiar angular distributions and identical RMS roughness are likely to scatter light differently. In our case the average texture angle is very close to $45^{\circ}$, which would limit such an effect [46].

No major differences are evident between the investigated materials and process conditions. RMS roughness and coherence length $\mathrm{L}$ of all textures are close to $100 \mathrm{~nm}$ and $300 \mathrm{~nm}$, respectively.
These values are comparable with values of similar UVNIL textures on glass substrates found to provide the highest photo-current compared to other textures with higher RMS roughness [28]. A closer look at the individual RMS roughness reveals slight influence of nanoparticle loading and process pressure on texture geometry.

Two main factors control the replication fidelity of UV cured nanocomposites: polymer shrinkage and residual stress. Shrinkage occurs essentially through the thickness of the coating due to in-plane confinement of the composite material in the mold, and is thus associated with changes in RMS roughness. The stress in the nanocomposite material during processing combines a hydrostatic component due to pressure confinement and an in-plane component due to restricted shrinkage. In the absence of nanoparticles the residual stress was very low (1.6 MPa for a similar acrylated HBP [25]), and the shape fidelity was governed by the shrinkage during polymerization. The result was a lower value of the RMS roughness as seen in Table 1 for the HBP with no silica 
particles. When nanoparticles were introduced in the polymer matrix, a balance between shrinkage and residual stress took place. The shrinkage, which occurred along the vertical dimension of the pyramids was less pronounced and RMS roughness stayed closer to the value for the Nickel master. The increase in L values with increasing silica fraction was within experimental error, although it would correlate with increasing residual stress [25]. Relaxation processes upon demolding led to a complex 3D residual stress state, with distortion effects associated with changes in $L$ values [47]. No clear effect of process pressure during photo-polymerization was observed. This finding is consistent with the fact that the HBP nanocomposites are yield stress fluids, which start to flow under a stress above a threshold 'yield'

Table 1

RMS roughness, coherence length $L$ and haze of Ni master and texturized HBP and HBP nanocomposites.

\begin{tabular}{lllll}
\hline $\begin{array}{l}\text { Silica } \\
\text { fraction } \\
\text { (vol\%) }\end{array}$ & $\begin{array}{l}\text { Process } \\
\text { pressure } \\
\text { (bar) }\end{array}$ & $\begin{array}{l}\text { RMS } \\
\text { roughness } \\
(\mathrm{nm})\end{array}$ & $\begin{array}{l}\text { Coherence } \\
\text { length } L \\
(\mathrm{~nm})\end{array}$ & $\begin{array}{l}\text { Haze (average over } \\
400-800 \mathrm{~nm})(-)\end{array}$ \\
\hline Ni master & - & 101 & 301 & 0.893 \\
0 & 1 & 71.2 & 239 & 0.903 \\
0 & 3 & 75.1 & 254 & 0.912 \\
0 & 6 & 66.9 & 249 & 0.900 \\
10 & 1 & 96.0 & 348 & 0.899 \\
10 & 3 & 90.3 & 391 & 0.905 \\
10 & 6 & 121 & 363 & 0.903 \\
20 & 1 & 103 & 345 & 0.902 \\
20 & 3 & 89.7 & 421 & 0.902 \\
20 & 6 & 102 & 366 & 0.898 \\
\hline
\end{tabular}

stress. The yield stress of the nanocomposite with $20 \mathrm{vol} \%$ of silica is equal to approximately $50 \mathrm{kPa}$ [24], which is indeed lower than the lowest investigated pressure of 1 bar. A pressure as low as $50 \mathrm{kPa}(0.5 \mathrm{bar})$ should therefore be sufficient to ensure complete filling of the texturized mold.

The success of the light scattering process relies on light reflected at larger angles than the escape limit, so as to maximize the number of photons trapped inside the cell structure. Consequently, a better efficiency should be reached when more light is scattered at larger angles [6]. The ARS measurements of the nickel master and the polymer-based textures are compiled in Fig. 5. The left column in the figure shows the influence of process pressure for given silica content, while the right column shows the influence of silica content for a fixed pressure.

The peak present below a scattering angle of $15^{\circ}$ corresponds to the specular reflection. A substantial amount of light was diffused at angles greater than $15^{\circ}$ and the behavior was similar in all cases with a progressive decay to the maximum angle of $70^{\circ}$. The optical properties of the HBP textures with no silica particles were identical to that of the master for all investigated pressures. In contrast, nanocomposite textures showed a drop in the quantity of light collected by the photodetector, and this behavior was emphasized at higher pressure. Again, these changes in optical performance reflected the influence of the process-induced internal stress.

A similar tendency is observed in the total reflectance results reproduced in Fig. 6, with a deviation from the properties of the master for increasing imprinting pressure and silica content. The diffuse reflection (not shown in the figure) also displayed the same deviation. As a consequence, and in contrast to the ARS

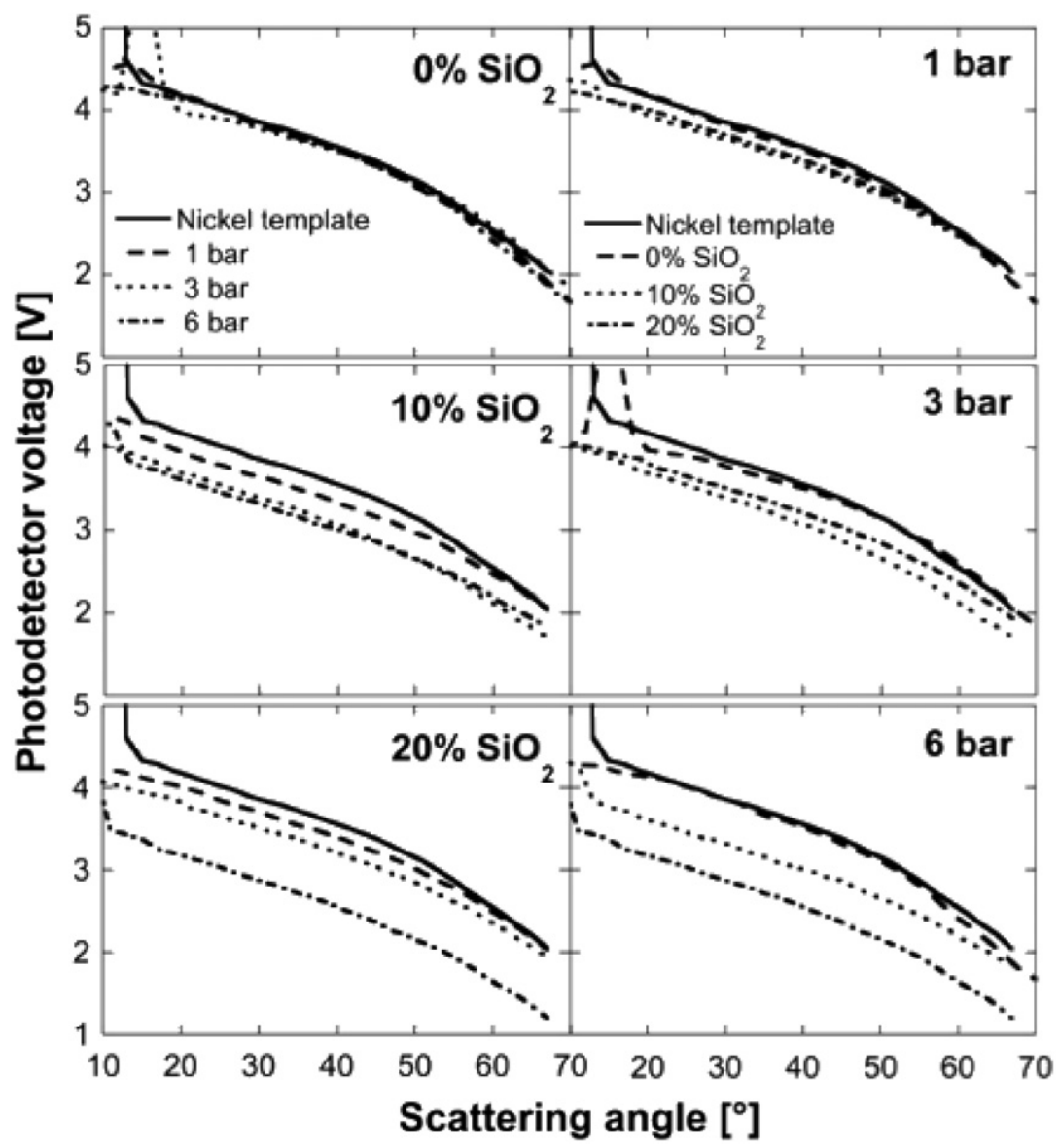

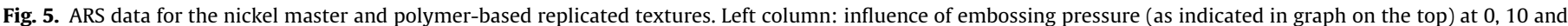
20 vol\% of silica. Right column: influence of silica content (as indicated in graph on the top) at 1, 3 and 6 bars. 


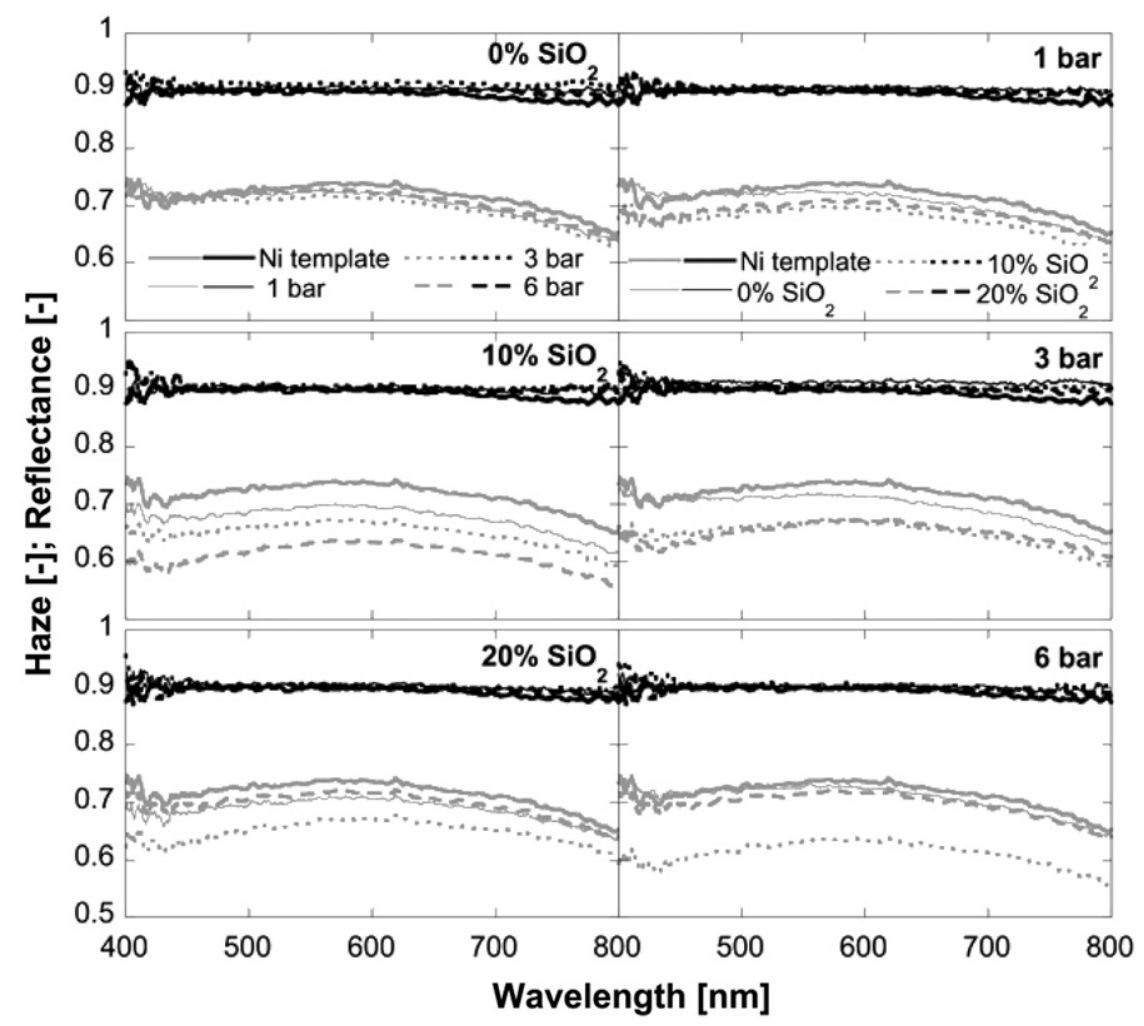

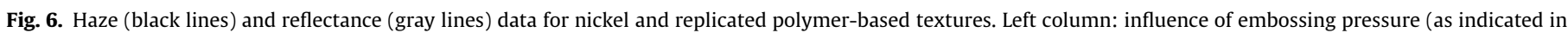
graph on the top) at 0,10 and $20 \mathrm{vol} \%$ of silica. Right column: influence of silica content (as indicated in graph on the top) at 1,3 and 6 bars.

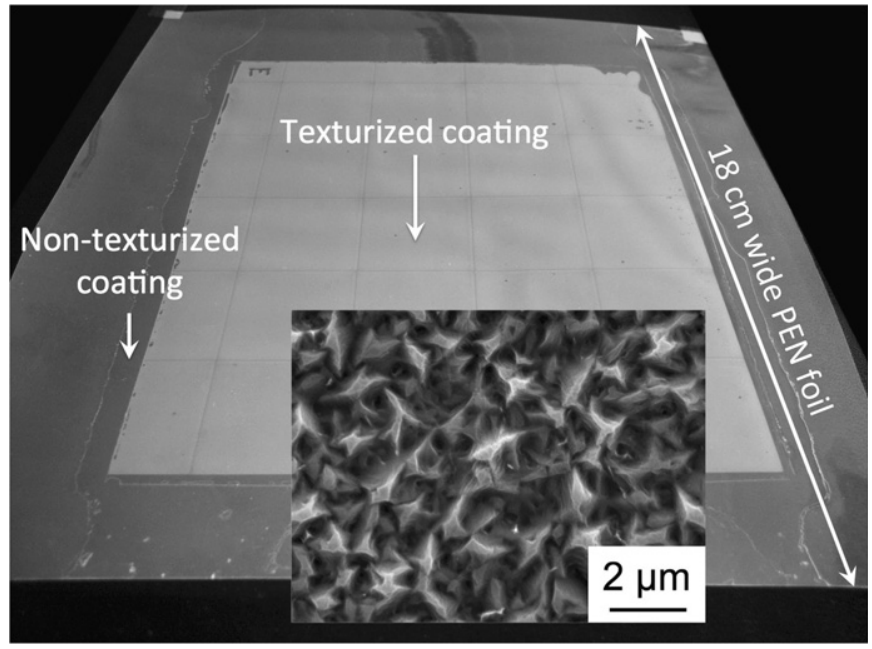

Fig. 7. Texturized HBP coating on a $18 \mathrm{~cm}$ wide PEN foil. The inset is a top view of the texture.

and reflectance behavior, the haze of all polymer-based textures was identical to that of the master over most of the frequency range (Table 1 ).

To summarize, the HBP nanocomposites are twice as hard compared to the HBP and they replicate with a very high fidelity the nickel master, even at high loadings of nanoparticles. The nanocomposite textures effectively scatter light at large incidences and their haze is close to $90 \%$ across the whole spectral range, which is within less than $2 \%$ of the haze of the metal master.

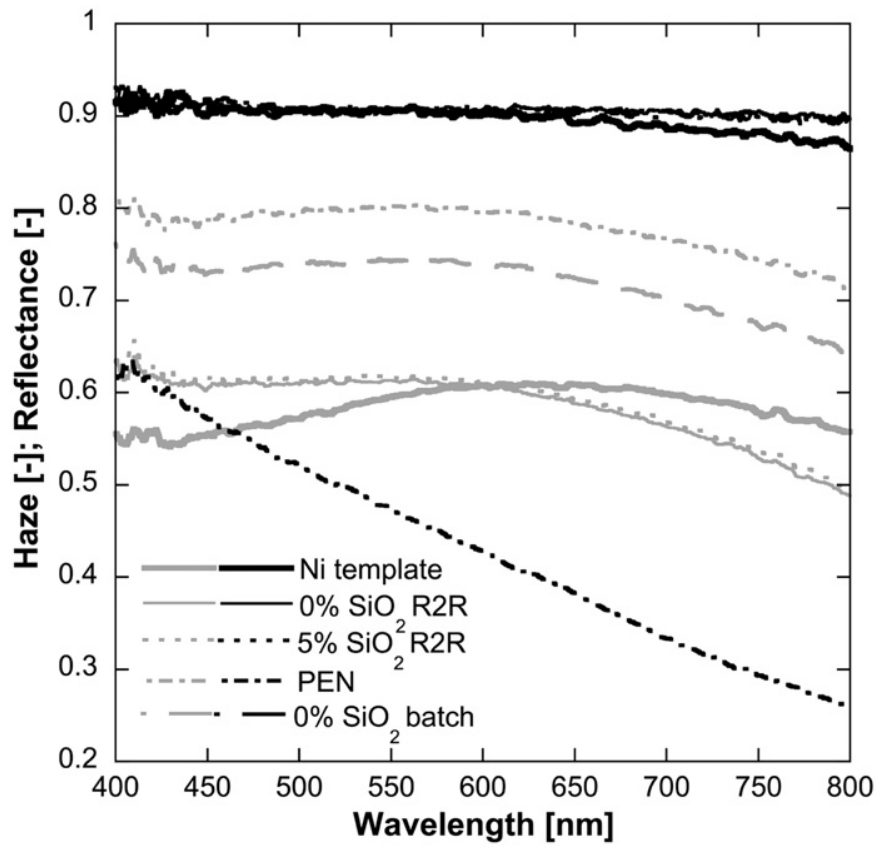

Fig. 8. Haze (black lines) and reflectance (gray lines) data for nickel template, PEN, batch texturized HBP and roll-to-roll texturized HBP and HBP nanocomposite ( 5 vol\% silica).

\subsection{Roll-to-roll production of photovoltaic devices}

A $11 \mathrm{~cm} \times 13 \mathrm{~cm}$ sample of texturized HBP coating on the $18 \mathrm{~cm}$ wide PEN substrate placed over a black support, and under 
a

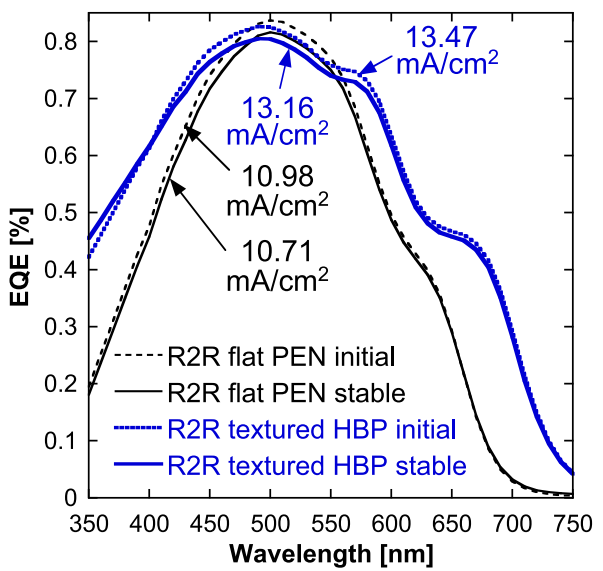

b

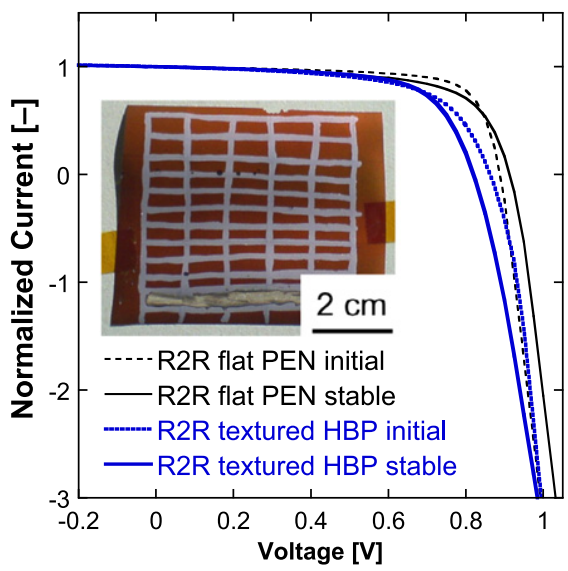

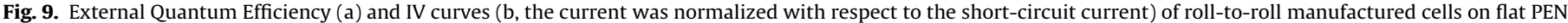

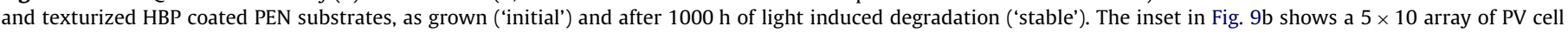
samples. (For interpretation of the references to color in this figure, the reader is referred to the web version of this article.)

Table 2

PV parameters of roll-to-roll processed cells on flat PEN and texturized HBP coated PEN substrates, as grown (initial state) and after $1000 \mathrm{~h}$ of light induced degradation (stable state).

\begin{tabular}{lllll}
\hline Substrate & $V_{\text {oc }}[\mathrm{V}]$ & $J_{\text {sc }}\left[\mathrm{mA} / \mathrm{cm}^{2}\right]$ & FF [-] & Efficiency [\%] \\
\hline Flat PEN (initial) & 0.89 & 10.98 & 73.2 & 7.15 \\
Flat PEN (stable) & 0.91 & 10.71 & 65.1 & 6.38 \\
Texturized HBP (initial) & 0.82 & 13.47 & 65.9 & 7.27 \\
Texturized HBP (stable) & 0.86 & 13.16 & 61.6 & 7.00 \\
\hline
\end{tabular}

day light illumination is shown in Fig. 7. A very high and homogeneous haze effect is evident.

Fig. 8 shows the reflectance and haze of the roll-to-roll texturized HBP shown in Fig. 7 and roll-to-roll texturized nanocomposite ( $5 \mathrm{vol} \%$ silica). The optical properties of the nickel template (Fig. 4a), of the batch texturized HBP (Fig. 4b) and of the PEN substrate are also displayed for comparison. The reflectance of the PEN was the highest of all investigated materials, and its haze was the lowest, with a marked decrease at increasing wavelength. The reflectance of the roll-to-roll texturized HBP was 15\% lower than that of the batch texturized HBP, which essentially resulted from the different nature of the aluminum layer used for the integrated sphere measurement (sputtered for the batch textures and evaporated for the roll-to-roll textures [48]). In spite of this difference, the haze of both batch and roll-to-roll texturized HBP was identical. It is also evident that the addition of $5 \mathrm{vol} \%$ of silica nanoparticles had no detectable effect on the reflectance and haze of the roll-to-roll textures.

The spectral and IV responses of PV cells deposited on a flat PEN and a texturized HBP coated PEN substrate, as grown and after $1000 \mathrm{~h}$ of light induced degradation are compared in Fig. 9. The inset in Fig. 9b shows an array of cell samples. The current was normalized with respect to the short circuit current and the IV data are averages of 10-15 individual cells. The optical absorption was enhanced by the texturized back contact, both in the blue and red regions (Fig. 9a). The corresponding shortcircuit current density $J_{\mathrm{sc}}$, open-circuit voltage $V_{\mathrm{oc}}$ and fill factor FF are reported in Table 2 . The texturized back reflector led to a $23 \%$ improvement of $J_{\mathrm{sc}}$, from $11 \mathrm{~mA} / \mathrm{cm}^{2}$ for the flat reflector reference to $13.5 \mathrm{~mA} / \mathrm{cm}^{2}$ for the texturized reflector. After degradation the devices stabilized to 10.7 and $13.2 \mathrm{~mA} / \mathrm{cm}^{2}$, respectively, i.e. the same $23 \%$ increase was achieved for stabilized cells. The initial efficiency compared with the flat reflector reference was only marginally improved, since no particular attention was paid to adjust the deposition parameters of the cell in order to increase $V_{\text {oc }}$ and FF.

The morphology of the device shown in Fig. 10 is characterized by a good conformal coverage with smooth interfaces and absence of a-Si growth defects in the bottom of the valleys. Such morphology based on a texture with RMS roughness close to $100 \mathrm{~nm}$ and rather wide pyramidal angles is optimal for cell performance [28].

\section{Conclusions}

Nanocomposite coatings based on an acrylated HBP and silica nanoparticles were developed to create light-trapping textures using a UVNIL replication method. The hardness of the coating material was found to increase from $112 \mathrm{MPa}$ for the plain HBP to $280 \mathrm{MPa}$ for the composite with $50 \mathrm{vol} \%$ of silica. A homogeneous distribution of nanoparticles throughout the thickness of the coating was achieved, without exudation of a HBP rich layer on the texturized surface. Both HBP and HBP nanocomposites with up to $20 \mathrm{vol} \%$ of silica replicated the sub-micron pyramids of the nickel master with excellent fidelity. The nanocomposite textures effectively scattered light at large incidences and their haze was close to $90 \%$ across the whole spectral range for all tested compositions and process pressures. A small drop in the amount of scattered light was observed at high nanoparticle fraction and high process pressure, due to internal stress effects. Moreover, an $18 \mathrm{~cm}$ wide web roll-to-roll process was developed in view of cost-effective production of large area texturized coatings on a PEN substrate. The haze of roll-to-roll texturized HBP and HBP nanocomposite was identical to that of batch produced textures. Thin film silicon solar cells were deposited on roll-to-roll texturized HBP coated PEN, with an increase of $23 \%$ in photocurrent compared to a flat cell.

The present work demonstrates that a roll-to-roll UVNIL is an effective process to enable significant increase of the current density in a-Si devices. The addition of nanoparticles to the UV resin did not compromise the fidelity of the replication process, and enabled a 2.5 times increase of the surface hardness of the coated PEN substrate. This combination of properties is expected 

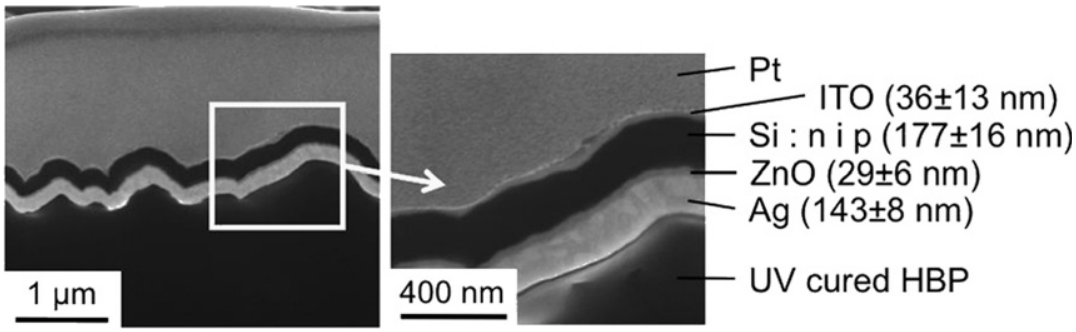

Fig. 10. Electron micrograph of a FIB cross-section of a roll-to-roll processed a-Si device on texturized HBP coating.

to be beneficial for the mechanical integrity and PV performance of such thin film devices on flexible polymer substrates.

\section{Acknowledgments}

The authors acknowledge the Swiss Commission for Technology and Innovation (CTI, project 9903.1 PFIW-IW) for financial support.

\section{References}

[1] H.W. Deckman, C.R. Wronski, H. Witzke, E. Yablonovitch, Optically enhanced amorphous silicon solar cells, Applied Physics Letters 42 (1983) 968-970.

[2] C. Rockstuhl, S. Fahr, K. Bittkau, T. Beckers, R. Carius, F.J. Haug, T. Soderstrom, C. Ballif, F. Lederer, Comparison and optimization of randomly textured surfaces in thin-film solar cells, Optics Express 18 (2010) A335-A342.

[3] R.H. Franken, R.L. Stolk, H. Li, C.H.M. van der Werf, J.K. Rath, R.E.I. Schropp, Understanding light trapping by light scattering textured back electrodes in thin film n-i-p-type silicon solar cells, Journal of Applied Physics 102 (2007) 014503-014507.

[4] A.W. Smith, A. Rohatgi, Ray tracing analysis of the inverted pyramid texturing geometry for high efficiency silicon solar cells, Solar Energy Materials and Solar Cells 29 (1993) 37-49.

[5] J. Krc, M. Zeman, F. Smole, M. Topic, Optical modeling of a-Si:H solar cells deposited on textured glass/SnO2 substrates, Journal of Applied Physics 92 (2002) 749-755.

[6] H. Stiebig, M. Schulte, C. Zahren, C. Haase, B. Rech, P. Lechner, Light trapping in thin-film silicon solar cells by nano-textured interfaces, Proceedings of SPIE 6197 (2006) 6197011-6197019.

[7] P. Campbell, M.A. Green, Light trapping properties of pyramidally textured surfaces, Journal of Applied Physics 62 (1987) 243-249.

[8] K. Söderström, J. Escarré, O. Cubero, F.J. Haug, S. Perregaux, C. Ballif, UV-nanoimprint lithography technique for the replication of back reflectors for $n-i-p$ thin film silicon solar cells, Progress in Photovoltaics: Research and Applications 19 (2011) 202-210.

[9] C. Battaglia, J. Escarre, K. Soderstrom, M. Charriere, M. Despeisse, F.J. Haug C. Ballif, Nanomoulding of transparent zinc oxide electrodes for efficient light trapping in solar cells, Nature Photonics 5 (2011) 535-538.

[10] S. Faÿ, J. Steinhauser, N. Oliveira, E. Vallat-Sauvain, C. Ballif, Opto-electronic properties of rough LP-CVD ZnO:B for use as TCO in thin-film silicon solar cells, Thin Solid Films 515 (2007) 8558-8561.

[11] M. Fonrodona, J. Escarré, F. Villar, D. Soler, J.M. Asensi, J. Bertomeu, J. Andreu, PEN as substrate for new solar cell technologies, Solar Energy Materials and Solar Cells 89 (2005) 37-47.

[12] S.Y. Chou, P.R. Krauss, W. Zhang, L. Guo, L. Zhuang, Sub-10 nm imprint lithography and applications, Journal of Vacuum Science and Technology B: Microelectronics and Nanometer Structures 15 (1997) 2897-2904.

[13] J. Escarre, J. Bertomeu, J.M. Asensi, J. Andreu, V. Terrazzoni-Daudrix, F.J. Haug, $\mathrm{X}$. Niquille, Hot embossing of polymer substrates for thin silicon cell applications, in: Proceedings of the 2006 IEEE 4th World Conference on Photovoltaic Energy Conversion, 2006, pp. 1556-1559.

[14] B. Vratzov, A. Fuchs, M. Lemme, W. Henschel, H. Kurz, Large scale ultravioletbased nanoimprint lithography, Journal of Vacuum Science and Technology B: Microelectronics and Nanometer Structures 21 (2003) 2760-2764.

[15] S.H. Ahn, L.J. Guo, High-speed roll-to-roll nanoimprint lithography on flexible plastic substrates, Advanced Materials 20 (2008) 2044-2049.

[16] L. Schmidt, D. Schmäh, Y. Leterrier, J.-A. Månson, Time-intensity transformation and internal stress in UV-curable hyperbranched acrylates, Rheologica Acta 46 (2007) 693-701.

[17] L.E. Schmidt, S. Yi, Y.-H. Jin, Y. Leterrier, Y.-H. Cho, J.-A.E. Månson, Acrylated hyperbranched polymer photoresist for ultra-thick and low-stress high aspect ratio micropatterns, Journal of Micromechanics and Microengineering 18 (2008) 045022.

[18] F. Hussain, M. Hojjati, M. Okamoto, R.E. Gorga, Review article: polymermatrix nanocomposites, processing, manufacturing, and application: an overview, Journal of Composite Materials 40 (2006) 1511-1575.
[19] M.C. Kuo, C.M. Tsai, J.C. Huang, M. Chen, PEEK composites reinforced by nano-sized $\mathrm{SiO}_{2}$ and $\mathrm{Al}_{2} \mathrm{O}_{3}$ particulates, Materials Chemistry and Physics 90 (2005) 185-195.

[20] H. Sugimoto, K. Daimatsu, E. Nakanishi, Y. Ogasawara, T. Yasumura, K. Inomata, Preparation and properties of poly(methylmethacrylate)-silica hybrid materials incorporating reactive silica nanoparticles, Polymer 47 (2006) 3754-3759.

[21] V. Geiser, Y. Leterrier, J.-A.E. Månson, Conversion and shrinkage analysis of acrylated hyperbranched polymer nanocomposites, Journal of Applied Polymer Science 114 (2009) 1954-1963.

[22] Y. Leterrier, L. Médico, F. Demarco, J.A.E. Månson, U. Betz, M.F. Escola, M.K. Olsson, F. Atamny, Mechanical integrity of transparent conductive oxide films for flexible polymer-based displays, Thin Solid Films 460 (2004) 156-166.

[23] Y. Leterrier, A. Pinyol, D. Gilliéron, J.A.E. Månson, P.H.M. Timmermans, P.C.P. Bouten, F. Templier, Mechanical failure analysis of thin film transistor devices on steel and polyimide substrates for flexible display applications, Engineering Fracture Mechanics 77 (2010) 660-670.

[24] V. Geiser, Y. Leterrier, J.-A.E. Månson, Rheological behavior of concentrated hyperbranched polymer/silica nanocomposite suspensions, Macromolecules 43 (2010) 7705-7712.

[25] V. Geiser, Y.-H. Jin, Y. Leterrier, J.-A.E. Månson, Nanoimprint lithography with UV-curable hyperbranched polymer nanocomposites, Macromolecular Symposia 296 (2010) 144-153.

[26] J.R. Condon, J.L. Ferracane, Assessing the effect of composite formulation on polymerization stress, The Journal of the American Dental Association 131 (2000) 497-503.

[27] V. Geiser, Y. Leterrier, J.-A.E. Månson, Low-stress hyperbranched polymer/silica nanostructures produced by uv-curing, sol-gel processing and nanoimprint lithography, Macromolecular Materials and Engineering 297 (2012) 155-166.

[28] P. Couty, M. Duchamp, K. Söderström, A. Kovács, R.E. Dunin-Borkowski, L. Sansonnens, Y. Ziegler, Transmission electron microscopy of amorphous tandem thin-film silicon modules produced by a roll-to-roll process on plastic foil, in: Proceedings of the 26th EU PVSEC, 5-9 September 2011, Hamburg, Germany, 2011.

[29] M. Izu, T. Ellison, Roll-to-roll manufacturing of amorphous silicon alloy solar cells with in situ cell performance diagnostics, Solar Energy Materials and Solar Cells 78 (2003) 613-626.

[30] F.J.B. Calleja, S. Fakirov, Microhardness of Polymers, Cambridge University Press, 2000.

[31] V.T. Daudrix, J. Guillet, F. Freitas, A. Shah, C. Ballif, P. Winkler, M. Ferreloc, S. Benagli, X. Niquille, D. Fischer, R. Morf, Characterisation of rough reflecting substrates incorporated into thin-film silicon solar cells, Progress in Photovoltaics: Research and Applications 14 (2006) 485-498.

[32] M. Raspanti, E. Binaghi, I. Gallo, A. Manelli, A vision-based, 3D reconstruction technique for scanning electron microscopy: direct comparison with atomic force microscopy, Microscopy Research and Technique 67 (2005) 1-7.

[33] J. Löberg, I. Mattisson, S. Hansson, E. Ahlberg, Characterisation of titanium dental implants I: critical assessment of surface roughness parameters, The Open Biomaterials Journal 2 (2010) 18-35.

[34] F. Elsholz, E. Scholl, A. Rosenfeld, Kinetic Monte Carlo simulations of amorphous thin-film growth, Physica Status Solidi B: Basic Solid State Physics 244 (2007) 3639-3646.

[35] I. Horcas, R. Fernandez, J.M. Gomez-Rodriguez, J. Colchero, J. Gomez-Herrero, A.M. Baro, WSXM: a software for scanning probe microscopy and a tool for nanotechnology, Review of Scientific Instruments 78 (2007) 013705-013708.

[36] R.K. Goyal, A.N. Tiwari, Y.S. Negi, Microhardness of PEEK/ceramic micro- and nanocomposites: correlation with Halpin-Tsai model, Materials Science and Engineering: A 491 (2008) 230-236.

[37] B. Ramezanzadeh, M. Attar, M. Farzam, Effect of $\mathrm{ZnO}$ nanoparticles on the thermal and mechanical properties of epoxy-based nanocomposite, Journal of Thermal Analysis and Calorimetry 103 (2011) 731-739.

[38] R.W. Rice, P.W. McMillan, A.J. Stryjak, Internal stress dependence of the hardness of crystallized glasses, Journal of Materials Science 14 (1979) 2768-2772.

[39] J.M. Antunes, A. Cavaleiro, L.F. Menezes, M.I. Simões, J.V. Fernandes, Ultramicrohardness testing procedure with Vickers indenter, Surface and Coatings Technology 149 (2002) 27-35.

[40] D. Hull, An Introduction to Composite Materials, Cambridge University Press, Cambridge, UK, 1981. 
[41] Z. Hashin, S. Shtrikman, A variational approach to the theory of the elastic behaviour of polycrystals, Journal of the Mechanics and Physics of Solids 10 (1962) 343-352.

[42] P.P. Castaneda, G. Debotton, On the homogenized yield strength of two-phase composites, Proceedings of the Royal Society of London, Series A: Mathematical and Physical Sciences 438 (1992) 419-431.

[43] Z.G. Pandermarakis, G. Spathis, An homogenization procedure for the description of pre- and post-yielding stages of isotropic polymer composites, Polymer Composites 29 (2008) 978-991.

[44] B. Turcsányi, B. Pukánszky, F. Tüdõs, Composition dependence of tensile yield stress in filled polymers, Journal of Materials Science Letters 7 (1988) 160-162.

[45] K.W. Desmond, E.R. Weeks, Random close packing of disks and spheres in confined geometries, Physical Review E 80 (2009) 051305.
[46] C. Battaglia, K. Söderström, J. Escarre, F.-J. Haug, D. Domine, P. Cuony M. Boccard, G. Bugnon, C. Denizot, M. Despeisse, A. Feltrin, C. Ballif, Efficient light management scheme for thin film silicon solar cells via transparent random nanostructures fabricated by nanoimprinting, Applied Physics Letters 96 (2010). 213504-213503.

[47] M.B. Chan-Park, Y.C. Lam, P. Laulia, S.C. Joshi, Simulation and investigation of factors affecting high aspect ratio UV embossing, Langmuir: the ACS Journal of Surfaces and Colloids 21 (2005) 2000-2007.

[48] H. Du, J.Q. Xiao, Y.S. Zou, T.G. Wang, J. Gong, C. Sun, L.S. Wen, Optical properties of ultrathin aluminum films deposited by magnetron sputtering in visible band, Optical Materials 28 (2006) 944-949. 